\title{
Hyperpigmentation of Tongue Associated with Hepatitis C Treatment
}

Aşkın Erdoğan', Leyla Kansu², Hampar Akkaya³

${ }^{1}$ Department of Gastroenterology, Başkent University Faculty of Medicine, Antalya, Turkey

${ }^{2}$ Department of Otolarynngology-Head and Neck Surgery, Başkent University Faculty of Medicine, Antalya, Turkey

${ }^{3}$ Deparment of Pathology, Başkent University Faculty of Medicine, Antalya, Turkey

\section{Case Report}

A 55-year-old white woman receiving peginterferon alfa2a (180 mg) and ribavirin (1200 mg) combination therapy for hepatitis $\mathrm{C}$ virus ( $\mathrm{HCV}$; genotype $1 \mathrm{~b}$ ) infection complained of a burning sensation and discomfort in her tongue in the second month, and tongue hyperpigmentation in the fourth month of the therapy. Physical examination revealed hyperpigmentation on the lateral and dorsal parts of the tongue (Figure 1). There was no hyperpigmentation on any other part of her body. Tongue biopsy was performed to exclude other causes, which revealed minimal parakeratosis, irregular acanthosis, melanin pigment and macrophage accumulation of subepithelial connective tissue, and also focal chronic inflammation (Figure 2).

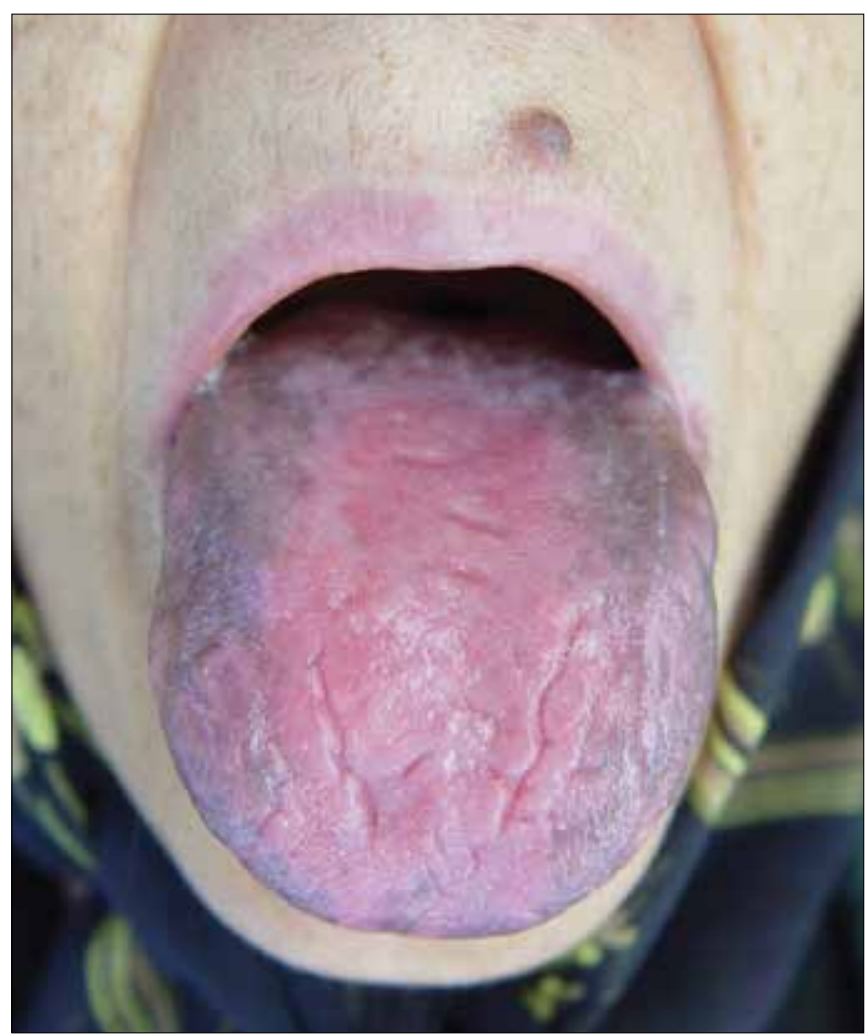

Figure 1. Physical examination showed hyperpigmentation on the lateral and dorsal parts of the tongue
No other reason was detected for hyperpigmentation. At the beginning of the therapy, HCV RNA level was $5.54 \times 10^{5} \mathrm{IU} /$ $\mathrm{mL}$. Therapy was continued for 48 weeks. She was negative for HCV RNA in the first month after the therapy, but positive in the third and sixth months after the therapy. Despite active $\mathrm{HCV}$ infection, the tongue hyperpigmentation resolved completely after the end of the therapy.

\section{Discussion}

Skin changes such as lichen planus, porphyria cutanea tarda, chronic pruritus, and cutaneous necrotising vasculitis can be seen during the course of HCV infection. However, tongue hyperpigmentation is extremely rarely reported. Interferons increase the expression of surface melanocyte-stimulating hormone (MSH) receptors and in this way, via $\mathrm{MSH}$, increase melanin pigment production. Herein we report a white woman with hyperpigmentation of her tongue during peginterferon alfa-2a plus ribavirin therapy. Our case suggests that either interferon alone or together with ribavirin may be responsible for hyperpigmentation in HCV infection.

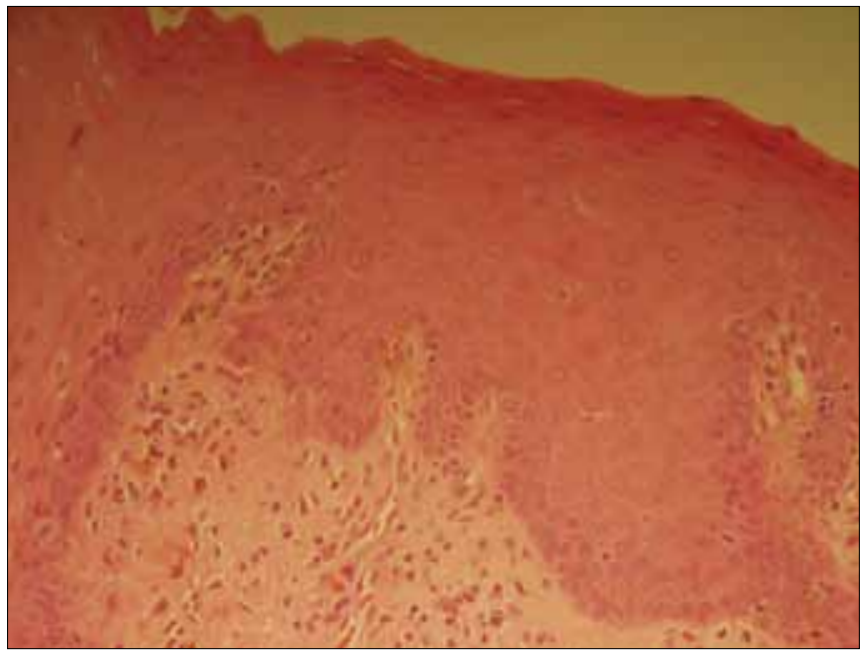

Figure 2. Tongue biopsy revealed minimal parakeratosis, irregular akanthosis, melanin pigment and macrophage accumulation of subepithelial tissue, and also focal chronic inflamation 
Ethics Committee Approval: Ethics committee approval was received for this study.

Informed Consent: Written informed consent was obtained from the patient.

Peer-review: Externally peer-reviewed.

Author contributions: Concept - A.E., L.K., H.A.; Design - A.E, L.K, H.A.; Supervision - A.E.; Resource - A.E., L.K., H.A.; Materials - A.E., L.K., H.A.; Data Collection\&/or Processing - A.E., L.K., H.A.; Analysis\&/or Interpretation - A.E., L.K., H.A.; Literature Search - A.E.; Writing - A.E.; Critical Reviews - A.E., L.K., H.A.
Conflict of Interest: No conflict of interest was declared by the authors. Financial Disclosure: No financial disclosure was declared by the authors.

\section{References}

1. Karabay O, Goksugur N, Ogutlu A. Tongue hyperpigmentation during interferon therapy. J Dermatol 2011;38:290-1. [CrossRef]

2. Mlika RB, Kerkeni N, Marrak H, Fenniche S, Mokhtar I, Debbiche A. Tongue hyperpigmentation during PEG-interferon-alfa/ ribavirin therapy in a non-Caucasian patient with chronic hepatitis C:a case report and review of the literature. Int J Dermatol 2013;52:643-4. [CrossRef] 